\title{
“北斗卫星导航系统数据分析与应用”专题 ·前言
}

北斗卫星导航系统(BDS) 是我国自主建立的全球卫星导航系统(GNSS), 它是继美国全球定位系统(GPS)、 俄罗斯格洛纳斯卫星导航系统(GLONASS)之后第 3 个成熟的卫星导航系统，与 GPS, GLONASS 以及欧洲正在 建设的 Galileo 系统一起形成了未来一段时间内 4 个主要的全球卫星导航系统, 已被联合国卫星导航委员会认 定为供应商. BDS 自 2012 年 12 月 26 日开始向我国及周边地区提供服务, 定位精度为 $10 \mathrm{~m}$, 测速精度为 $0.2 \mathrm{~m} / \mathrm{s}$, 授时精度为 $10 \mathrm{~ns}$.

BDS 由空间段、地面段和用户段 3 部分组成, 可在全球范围内全天候、全天时为各类用户提供高精度、 高可靠定位、导航、授时服务, 并具短报文通信能力. 其空间段包括 14 颗导航卫星, 5 颗分别分布于地球同步 轨道卫星(GEO)、5 颗倾斜地球同步轨道(IGSO)以及 4 颗中轨地球卫星轨道(MEO); 其地面段由分布于我国境 内的主控站、注入站、监测站组成. BDS 有一些不同于其他 GNSS 系统的顶层设计. 例如, BDS 向普通用户提 供基本导航 PNT 服务的同时, 还向用户提供差分和完好性增强服务; BDS 的星座是由 GEO, IGSO 和 MEO 3 类卫星混合而成的, 但地面监测网是区域性的. 为保证达到服务精度、连续性、完好性、可用性等系统设计指 标, 以及进一步提升服务性能, 需要建立和发展不同于 GPS 等其他 GNSS 的系统数据测量和处理方法. 有关 BDS 系统设计特点、主要工作原理以及信息处理方法和初步计算结果等相关内容, 《中国科学: 物理学 力学 天文学》期刊最近几年已陆续有相关文章作过介绍. 本专题的论文着眼于北斗卫星导航系统数据分析与应用, 以提升北斗服务性能, 同时也力求涉及一些 BDS 尚待深入研究的问题, 如 BDS 从区域向全球过渡面临的主要 问题及其解决思路等.

本专题由 11 篇论文组成，内容涉及 BDS 卫星钟差预报精度分析、BDS 站间时间同步误差计算、太阳风 暴期间 BDS 电离层模型优化、BDS 对全球电离层模型建立的贡献、在轨 BDS 卫星故障快速诊断与恢复、轨 位偏置的 GEO 卫星轨道快速恢复、BDS 相对定位中不同滤波方法的精度分析、BDS 基本导航电文定义与使 用方法、基于大数据技术的 BDS 信息服务性能提升、基于星间测距的全球 BDS 自主定轨以及基于广播星历 参数的 BDS 自主导航. 本专题收录的这些工作只代表了部分参与 BDS 建设与运行的青年学者们对提升 BDS 性能和水平所作的努力, 而与 BDS 相关的众多其他领域, 如导航信号、卫星平台、星载原子钟等方面的成果, 限于篇幅本专题无法包括.

GPS 作为最成熟的 GNSS 系统之一, 类似本专题论文中的基础科研在其 20 多年的不断完善过程中, 发挥 了非常重要的作用. 我们相信只要有更多学者愿意了解 BDS, 愿意针对 BDS 的系统特征开展更多的基础性研 究, BDS 将会是 GNSS 大家庭中领先的一员.

胡小工，廖新浩 中国科学院上海天文台

2015 年 5 月 